\title{
Quantifying the genetic parameters of feed efficiency in juvenile Nile tilapia Oreochromis niloticus
}

\author{
Hugues de Verdal ${ }^{1,2^{*}}$ (D, Marc Vandeputte ${ }^{3,4}$, Wagdy Mekkawy ${ }^{2,5}$, Béatrice Chatain ${ }^{4}$ and John A. H. Benzie 2,6
}

\begin{abstract}
Background: Improving feed efficiency in fish is crucial at the economic, social and environmental levels with respect to developing a more sustainable aquaculture. The important contribution of genetic improvement to achieve this goal has been hampered by the lack of accurate basic information on the genetic parameters of feed efficiency in fish. We used video assessment of feed intake on individual fish reared in groups to estimate the genetic parameters of six growth traits, feed intake, feed conversion ratio (FCR) and residual feed intake in 40 pedigreed families of the GIFT strain of Nile tilapia, Oreochromis niloticus. Feed intake and growth were measured on juvenile fish (22.4 g mean body weight) during 13 consecutive meals, representing 7 days of measurements. We used these data to estimate the FCR response to different selection criteria to assess the potential of genetics as a means of increasing FCR in tilapia.

Results: Our results demonstrate genetic control for FCR in tilapia, with a heritability estimate of $0.32 \pm 0.11$. Response to selection estimates showed FCR could be efficiently improved by selective breeding. Due to low genetic correlations, selection for growth traits would not improve FCR. However, weight loss at fasting has a high genetic correlation with FCR $(0.80 \pm 0.25)$ and a moderate heritability $(0.23)$, and could be an easy to measure and efficient criterion to improve FCR by selective breeding in tilapia.
\end{abstract}

Conclusion: At this age, FCR is genetically determined in Nile tilapia. A selective breeding program could be possible and could help enabling the development of a more sustainable aquaculture production.

Keywords: Feed conversion ratio, Tilapia, Heritability, Genetic estimations, Correlations

\section{Background}

A major issue confronting the world today is how to sustainably feed the world's rising human population (predicted to attain 9.6 billion in 2050) with less space available for farming [1]. Key components of strategies to address this problem include the use of novel sources of food such as insects, greater access to underutilized farming systems such as aquaculture and, most importantly, improving the efficiency of existing farming systems [2].

Farmed fish species offer a particular opportunity in this regard. Aquaculture production has grown rapidly

\footnotetext{
* Correspondence: hugues.de_verdal@cirad.fr

${ }^{1}$ CIRAD, UMR116 ISEM, TA B-116/16, 73 rue Jean-François Breton, 34398 Montpellier Cedex 5, France

${ }^{2}$ Worldfish, Jalan Batu Maung, 11960 Bayan Lepas, Penang, Malaysia Full list of author information is available at the end of the article
}

in the last 40 years and world production of farmed fish in 2012 was 74 million tons [3], similar to the global production of beef cattle [4]. These farmed fish used around six times less feed than beef cattle to produce the same amount of body mass [5, 6] Improved efficiency of fish production would provide even more benefit and enable further sustainable development of a still underutilized food production system. However, lack of adequate technology for recording feed efficiency in aquatic species and consequently, lack of information on its basic genetic parameters in fish is a key impediment to the implementation of selective breeding required to achieve this goal.

The single greatest cost in intensive fish farming systems is feed, ranging from 30 to $70 \%$ of the total production costs $[7,8]$. Reducing feed consumption for a given productivity level is therefore key to achieve economic

(c) The Author(s). 2018 Open Access This article is distributed under the terms of the Creative Commons Attribution 4.0 International License (http://creativecommons.org/licenses/by/4.0/), which permits unrestricted use, distribution, and 
sustainability of fish farming [9]. At the environmental level, improved feed efficiency is expected to have strong positive impacts at different levels. First, through a reduction of the amount of resources used, including fish oil and fish meals, thus contributing to the preservation of marine ecosystems. A better feed efficiency would also reduce nutrient outputs (nitrogen, phosphorus) that can be detrimental to the environment [10]. Finally, reducing feed consumption would also reduce energy consumption and greenhouse gases emissions due to feed production [11]. From a social perspective, improving feed efficiency (FE) in animal production should lead to a reduction of the competition for raw materials between humans and animals, and increase the quantity of food for humans, particularly the poorest, enhancing their access to proteins and balanced nutrition.

Feed efficiency can be improved through husbandry, feed formulation and by selective breeding. For example, rearing systems and feeding regimes can be customized to promote more efficient feed use and reduce unnecessary movement and therefore energy expenditure [1214]. Careful formulation of feeds can provide for more efficient digestion and utilization of feeds [15], and reduce the amounts of fish oils in diets [16].

Much of the historical gain on feed efficiency in livestock agricultural animals has been obtained indirectly through selection for growth rate [17]. However, in fish species, there is no clear results indicating an improvement of feed efficiency with a selective breeding programme on growth. Growth could contribute to improve feed efficiency, but all studies are not going in the same way $[8,18-22]$. Heritability estimates of feed efficiency in fish are scarce, and lower than in livestock $(0$ to $0.11[20,23]$ vs typically 0.21 to $0.30[24,25])$. This has been thought to reflect basic differences between (poikilotherm) fish and (homeotherm) livestock with different energy allocation strategies [20, 26].

While challenging to measure in terrestrial species, $\mathrm{FE}$, or more specifically feed conversion ratio $(\mathrm{FCR}=\mathrm{Feed}$ intake.body weight gain $^{-1}$, representing the quantity of fed consumed to produce one unit of biomass) is even more complicated to measure in fish. As fish are reared in large groups in water, it is not possible to collect uneaten feed and measure individual feed intake. Special feed labeled with X-ray dense markers has been the main method used to estimate feed intake in fish [2729]. Although noninvasive and accurate for a specific meal, the main disadvantages of this method are the stress associated with X-raying, but also the long recovery time (days or weeks) before the next possible assessment. This results in a relatively low repeatability of daily feed intake ( $r=0.09$ to $0.32[19,27,30,31])$ since fish are not eating the same amount of feed from one meal to another. This can however be overcome by multiple measurements over a long period of time [30, 31]. Video methods used to determine individual feed intake (FI) in groups of fish were assessed recently for tilapia by de Verdal et al. [32]. From this previous study, it appeared that feed intake measurements over 11 meals with two meals per day was necessary to achieve $95 \%$ repeatability. In the present study, five growth traits, feed intake, and feed efficiency traits were measured in pedigreed families of the GIFT strain of Nile tilapia, Oreochromis niloticus. We used these data to estimate genetic parameters as well as the expected correlated response to different selection criteria to assess the potential of genetics as a means of improving FCR in the second most farmed fish in the world.

\section{Methods}

Rearing of fish

The study was carried out on the GIFT (Genetically Improved Farmed Tilapia) strain of Nile tilapia [33] selected for growth using a rotational breeding scheme. The families were produced by natural spawning from December 2014 to December 2015 at the WorldFish Jitra Research station, Malaysia. The pedigree of each fish was registered for the genetic parameter estimations. The total pedigree file included 3383 fish from the 15 generations of GIFT (fish measured in the present study and their ascendants). The experiment was undertaken using four batches representing 40 families (8 families starting in June 2015; 8 families starting in November 2015; 12 families starting in February 2016; 12 families starting in April 2016).

After donation and transfer to the Penang WorldFish station, fish were reared until the fry reached approximately $10 \mathrm{~g}$ of body weight. After a week of quarantine in tanks, the beginning of the experiment consisted to place 30 fish per family in 2 distinct $100 \mathrm{~L}$ indoor tanks (120 cm length, $35 \mathrm{~cm}$ width and $24 \mathrm{~cm}$ depth) in a recirculating water system.

In total, 1200 fish were studied during this experiment. The average temperature was $28{ }^{\circ} \mathrm{C} \pm 1{ }^{\circ} \mathrm{C}$ and the photoperiod 12 L: 12D. After anesthesia with clove oil, each fish was tagged in the dorsal muscle with two colored T-bar tags (Avery Dennison tags, $25 \mathrm{~mm}$ ) using an Avery Dennison Mark III pistol Grip tool. Each fish in a tank was tagged with a unique colored T-bar tag to be able to identify each fish individually. Commercial feed with $34 \%$ of crude proteins, $5 \%$ of crude fat, $5 \%$ of crude fiber and $12 \%$ of moisture was used to feed the fish. A specific daily feed ration was used, calculated following the equation of Mélard, et al. [34]:

$$
\text { DFR }=14.23 * \text { Mean body weight }{ }^{-0.322}
$$

where DFR is the daily food ration (\% of body weight 
per day) and mean body weight was the average body weight of the 15 fish within each aquarium. Using this feed ration, fish were not underfed and no competition for feed was observed during the experiment. The use of this calculation was done because feeding the fish until apparent satiation can vary lot according to the observer, thus reducing repeatability of the measurements and increasing the tank effects. If a group of fish stopped to eat before the end of the daily feed ration, the uneaten pellets were removed from the aquarium.

Mortality was recorded daily and the feed ration changed accordingly. At the beginning of the refeeding period, a relative high mortality was observed (around 100 fish in total), probably because these fish were unable to get up after the stress of fasting.

\section{Experimental design and trait measurements}

The experimental protocol was previously described in details by de Verdal et al. [32] and is summarized in Fig. 1. Body weight was measured at the beginning and end of the four time periods shown in Fig. 1: adaptation period (15 days), fasting period (10 days), feeding period (17 days) and FI period (7 days). After being tagged, fish were kept in groups in their aquarium to be acclimated to their new rearing system for 15 days before the beginning of the experiment as an adaptation period. Then, during the fasting period, fish did not have any feed and the aim was to measure the loss of weight during fasting. Following a fasting period, fish tends to compensate the loss of growth lived during the fasting period and by increasing their growth more than normally. It is known as the compensatory growth period, here noted as feeding period. Finally, after the growth compensation, feed intake was measured accurately using video records during the FI period.

The difference of weight between the beginning and end of each period of measurement was calculated as the thermal growth coefficient (TGC), which uses the cubic relation between BW and length to make growth rate linear over time and corrected for the water temperature $(T)$ of the rearing environment during the measurement period:

$$
T G C=\left(B W_{2}^{(1 / 3)}-B W_{1}^{(1 / 3)}\right) /(T \times \Delta t) \times 100 .
$$

With $B W_{2}$ the body weight at the end of the period; $B W_{1}$ the body weight at the beginning of the period; $\mathrm{T}$ the rearing temperature and $\Delta t$ the number of days of the measured period. The TGC is widely used in fish to be able to compare the growth of different fish species with different optimal rearing temperature. The loss of weight during the fasting period was noted as $L_{O S S_{T G C}}$ and the gain of weight during the compensatory refeeding period was noted as $C O M P_{T G C}$.

After the compensatory growth period, FI was recorded for each fish over a period of 7 days (13 meals) to estimate feed efficiency traits as detailed in de Verdal et al. [32]. During this individual FI period, feed was delivered to each aquarium pellet by pellet by hand through two pipes by an observer screened from view in order reduce the closeness between the person who give the pellets and the aquarium. This was done twice daily at $7.00 \mathrm{am}$ and $1.00 \mathrm{pm}$. The first day, fish were weighed the morning and consequently, they received only one meal at $1.00 \mathrm{pm}$. Fish were fed until the calculated feed ration was finished. Video records of each meal was performed and video analyses were done to account for the number of pellets eaten by each individual fish during each meal. The day after the end of the FI measurement period, fish were anaesthetised with a high dose of clove oil and killed by decapitation. Fish were autopsied to measure different portions of the gastro-intestinal tract and sexed by visual observations of the gonads. The fish were too young to be reliably sexed using external morphology. Fish carcass were put in special bags, frozen and put in rendering wastes.

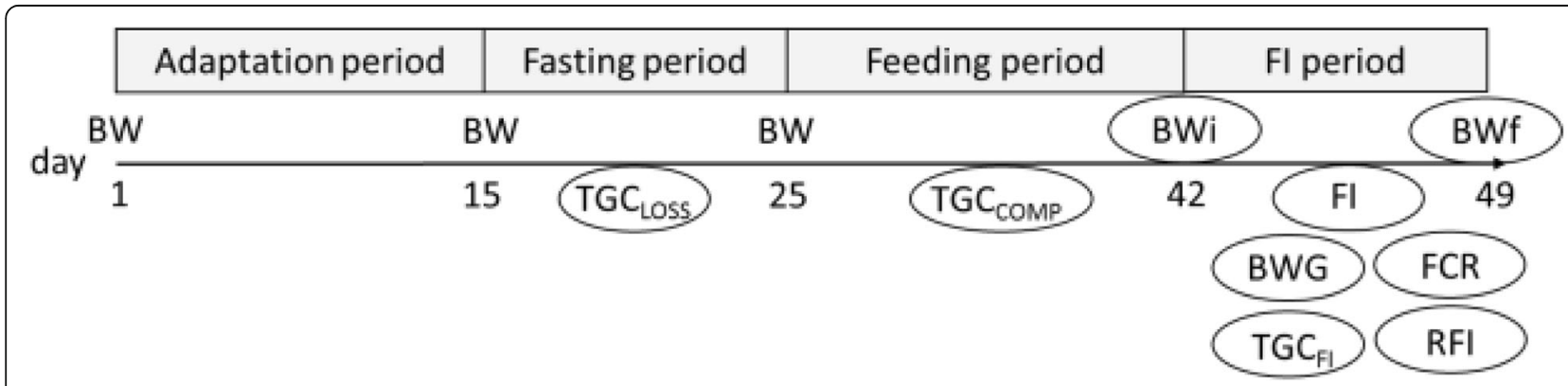

Fig. 1 - Scheme of the different periods (days) designed in the experimental protocol and corresponding traits measured in each period (in circle). BW: body weight measurement; TGC Loss: loss of weight during the fasting period estimated as thermal growth coefficient during the fasting period; TGC сомp: gain of weight during the feeding period estimated as the thermal growth coefficient during the refeeding period Fl: feed intake measured for each fish reared in group; BWG: body weight gain during the FI period; $\mathrm{TGC}_{\mathrm{Fl}}$ : thermal growth coefficient during the $\mathrm{Fl}$ period; FCR: feed conversion ratio during the FI period; RFI: residual feed intake during the Fl period 
The Kinovea 0.8.15 software (Copyright @ 2006-2011 - Joan Charmant \& Contrib.) was used to analyse the videos of the meals. The main advantage of this software was to be able to play with the speed of reading and the zoom of the video for more accuracy. After weighing 500 pellets ( $m e a n=16.4 \pm \mathrm{SD}=1.76 \mathrm{mg}, \mathrm{CV}=10.7 \%$ ), the choice was done to consider that the pellet weight variability was low enough to assume that all the pellets had the same weight, which give the opportunity to calculate FI in grams. The total FI for an individual was calculated as the sum of the FI of all meals consumed. The thermal growth coefficient during the period when the feed intake was individually measured was noted as $\mathrm{TGC}_{\mathrm{FI}}$. The body weight gain (BWG), during the feed intake measurement period was calculated as the difference in two body weight measurements taken at the beginning and end of the FI period.

The feed conversion ratio (FCR $=\mathrm{FI} / \mathrm{BWG}$ ) was used as an indicator of feed efficiency.

The residual feed intake (RFI) was calculated as the difference between the feed consumed by a fish and the prediction of the feed consumption of this fish using a regression model estimation, taking into account the feed required for maintenance and growth [35]. The equation used to estimate RFI was as follows:

$$
\begin{aligned}
\mathrm{RFI}= & \mathrm{FI}-\beta_{0}-\beta_{1} \times B W_{f}^{0.8}-\beta_{2} \\
& \times \mathrm{BWG}(\mathrm{r} 2 \text { of the model }=0.58)
\end{aligned}
$$

with, $\beta_{0}, \beta_{1}$ and $\beta_{2}$ are the intercept of the regression, the partial regression coefficient of animal's FI on metabolic body weight, and the partial regression coefficient of animal's FI on BWG (measured as $B W G=B W_{f}-B W_{i}$ ), respectively, $\mathrm{BW}^{0.8}$ is the metabolic body weight using 0.8 as the metabolic body coefficient, calculated by Lupatsch, et al. [36]. The more efficient fish are those with negative RFI, since these fish consume less than the average of fish with the same body weight and body weight gain whereas the less efficient fish are those with positive RFI, consuming more. The REG procedure of SAS (version 9.3, SAS Institute, Cary NC) was used to estimate the parameters of the regression equation.

\section{Estimation of genetic parameters}

Genetic parameters were estimated by the REML (Restricted Maximum Likelihood) method using the VCE6 software $[37,38]$. The following model was used for all the traits:

$$
\begin{aligned}
y_{i j k l}= & \mu+\text { Sex }_{i}+\text { Batch }_{j}+\text { Aquarium }_{k} \\
& + \text { Animal }_{l}+e_{i j k l}
\end{aligned}
$$

Where Sex $_{i}$ and Batch $_{j}$ are fixed effects, Aquarium $_{k}$ is a random environmental effect, and Animal ${ }_{l}$ is the random additive genetic effect of the animal $1(N=3383)$.
The pedigree file included animals from the 15 generations of the selection process. Significance of fixed effects was tested using SAS (GLM procedure). As the aquarium effect was a random effect, it represented the common environmental effect, taking into account the non-genetic effect of the family as the fixed effect of the aquarium. Some of the studied traits showed very strong genetic correlations with each other, it was not possible to run a multiple trait analysis that include all traits, meaning that distinct bivariate analyses were performed. A total of 36 analyses were performed with two traits each. When the genetic parameter of a trait was estimated several times, the average of the estimation obtained was calculated.

To estimate the impact of the selection criterion on the other traits, the following equation from Falconer and Mackay [39] was used to compare the expected direct and indirect correlated response to selection $\left(C R_{X}\right.$, $Y$ with $\mathrm{Y}$ the selection objective and $\mathrm{X}$ the selection criterion) on the different criteria:

$$
C R_{X, Y}=i_{X} \times \sqrt{\left(h_{X}^{2} \times h_{Y}^{2}\right)} \times r g_{X Y} \times \sigma_{P_{Y}}
$$

where $C R_{X, Y}$ is the expected correlated response of trait $\mathrm{Y}$ when selection is on $\mathrm{X} ; i_{X}$ is the intensity of selection on $\mathrm{X}$, considered equal for all the traits and estimated equal to 2.34 for the Nile tilapia selection breeding program in the present study (corresponding to $2.85 \%$ of fish kept as breeders for the next generation, as was previously done in the GIFT Nile tilapia breeding program); $h_{X}^{2}$ and $h_{Y}^{2}$ are the heritability estimated for $\mathrm{X}$ and $\mathrm{Y}$, respectively; $r g_{X Y}$ is the genetic correlation between $\mathrm{X}$ and $\mathrm{Y}$; and $\sigma_{P_{Y}}$ is the standard deviation of Y phenotype. For the direct expected response, $h_{X}^{2}$ and $h_{Y}^{2}$ were similar (since $\mathrm{X}$ and $\mathrm{Y}$ were confounded) and $r g_{X Y}$ was equal to 1. Expected responses to selection were expressed in units of trait $\mathrm{Y}$ to improve.

\section{Results}

\section{Phenotypic differences}

Feed intake was measured on 40 families of the GIFT strain of Nile tilapia, as well as four growth characteristics (Fig. 1 for more details on the traits). Fish weighed on average $22.4 \mathrm{~g}$ and $31.9 \mathrm{~g}$ at the beginning and at the end of the FI period, respectively. This represent a growth of $9.33 \mathrm{~g}$ during the 7 days of FI measurement, representing a TGC of 0.16 during this period. During the same period, fish fed on average $8.35 \pm 2.42 \mathrm{~g}$. During fasting and refeeding periods, the TGC were respectively -0.036 and 0.282 (with 24.9 and $17.5 \%$ of $\mathrm{CVs}$, respectively).

Feed conversion ratio (FCR) was estimated on 953 fish. The mean FCR was 0.94 ( $\mathrm{SD}=0.21)$, and a large $(22.1 \%)$ 
coefficient of variation (CV), close to that of body weight (Table 1). During the period of individual feed intake measurement, BWG was $10.3 \mathrm{~g}$ and $8.35 \mathrm{~g}$ for males and females, respectively, meaning that males grew $23.4 \%$ faster than females. Moreover, males consumed only $10.8 \%$ more feed than females during that period. In terms of FCR, males were significantly more efficient than females.

The phenotypic correlations between all the measured traits are shown in Table 2 (below the diagonal). Growth traits, except $\mathrm{TGC}_{\mathrm{LOSS}}$, were significantly and moderately to highly correlated with FI, with correlations ranged from 0.26 to 0.93 .

Feed conversion ratio and RFI (the residual feed intake) were highly phenotypically correlated $(\mathrm{rp}=0.83$ ), and FCR showed moderate phenotypic correlations with $\mathrm{BWG}$ and $\mathrm{TGC}_{\mathrm{FI}}$.

\section{Genetic parameters}

The genetic parameters for growth, FI, FCR and RFI are shown in Table 2. Except $\mathrm{TGC}_{\mathrm{FI}}$ and $\mathrm{TGC}_{\mathrm{LOSS}}$, heritability estimates were significant and moderate to high, ranging between $0.22 \pm 0.06$ for $\mathrm{TGC}_{\mathrm{COMP}}$ to $0.65 \pm 0.11$ for BWi. Feed intake, FCR and RFI showed significant moderate to high heritability, estimated at respectively $0.45 \pm$ $0.09,0.32 \pm 0.11$ and $0.50 \pm 0.10$.

Generally, the trend of genetic correlations (above the diagonal in Table 2) was consistent with phenotypic correlations. However, there were some exceptions. While the phenotypic correlations between BWG and FCR and RFI were negative and significant $(-0.46$ and -0.22 respectively), the genetic correlations between those traits were much lower and not significantly different from zero (from 0.07 to 0.33 in absolute values). On the other hand, there were low phenotypic correlations between FCR, RFI and $\mathrm{TGC}_{\mathrm{LOSS}}(0.09)$, but genetic correlations were all high ( 0.80 and 0.70 , respectively), making $\mathrm{TGC}_{\mathrm{LOSS}}$ a promising indirect indicator criterion for selection on FE.

Growth traits, except $\mathrm{TGC}_{\mathrm{COMP}}$ and $\mathrm{TGC}_{\mathrm{FI}}$, and $\mathrm{FI}$ were highly and positively correlated, with correlations ranged from 0.55 to 0.77 .

The genetic correlation between FCR and RFI was high $(0.97 \pm 0.03)$, suggesting that these two traits share the same genetic basis.

\section{Expected response to selection}

The expected responses to direct selection and indirect strategies on body weight, growth, feed intake, FCR and RFI are shown in Table 3, and are expressed in unit of improved trait.

Selection for body weight (BWi or BWf) would consistently improve all growth traits except $\mathrm{TGC}_{\mathrm{LOSS}}$ (with a gain equal to 85.7 to $138.6 \%$ of that of a direct selection for the target growth trait). Selection for BW would also increase FI by 91.5 to $96.9 \%$ of the gain that could be obtained by direct selection for FI (representing around $2 \mathrm{~g}$ of increase for the period of 13 meals measured). Due to the low genetic correlations between body weight and FCR and RFI, and to the increase of FI and BWG in the same time period, selection for body weight would only moderately improve FCR (by 0.015 and $0.023 \mathrm{~g} . \mathrm{g}^{-1}$ for BWf and BWi, respectively, representing an improvement of FCR of 1.60 and $2.45 \%$ per

Table 1 Basic statistics (LS Means \pm Standard Error) for all traits analysed

\begin{tabular}{|c|c|c|c|c|c|c|c|}
\hline \multirow[t]{2}{*}{ Trait $^{1}$} & \multirow[t]{2}{*}{ N } & \multirow[t]{2}{*}{ Mean \pm SD } & \multirow[t]{2}{*}{ Min } & \multirow[t]{2}{*}{ Max } & \multirow{2}{*}{$\begin{array}{l}\text { CV } \\
(\%)\end{array}$} & \multicolumn{2}{|l|}{ LS Means \pm SE } \\
\hline & & & & & & Males & Females \\
\hline \multicolumn{8}{|c|}{ Growth traits and feed intake } \\
\hline BWi & 1029 & $22.4 \pm 5.64$ & 7.74 & 40.15 & 25.1 & $23.4 \pm 0.17^{a}$ & $21.01 \pm 0.18^{b}$ \\
\hline BWf & 993 & $31.9 \pm 8.26$ & 10.04 & 56.61 & 25.9 & $33.7 \pm 0.26^{a}$ & $29.4 \pm 0.27^{b}$ \\
\hline TGC LOSS & 997 & $-0.036 \pm 0.01$ & -0.068 & 0.00 & 24.9 & $-0.036 \pm 0.001^{a}$ & $-0.036 \pm 0.001^{a}$ \\
\hline $\mathrm{TGC}_{\text {СомP }}$ & 995 & $0.282 \pm 0.049$ & 0.024 & 0.426 & 17.5 & $0.296 \pm 0.002^{a}$ & $0.265 \pm 0.002^{b}$ \\
\hline BWG & 981 & $9.33 \pm 3.14$ & 0.76 & 18.3 & 33.7 & $10.3 \pm 0.11^{\mathrm{a}}$ & $8.35 \pm 0.12^{b}$ \\
\hline $\mathrm{TGC}_{\mathrm{Fl}}$ & 993 & $0.16 \pm 0.04$ & 0.03 & 0.28 & 22.5 & $0.17 \pm 0.001^{\mathrm{a}}$ & $0.15 \pm 0.002^{b}$ \\
\hline $\mathrm{Fl}$ & 949 & $8.35 \pm 2.42$ & 1.80 & 15.6 & 29.0 & $9.05 \pm 0.09^{\mathrm{a}}$ & $8.17 \pm 0.09^{b}$ \\
\hline \multicolumn{8}{|c|}{ Feed efficiency traits } \\
\hline FCR & 953 & $0.94 \pm 0.21$ & 0.47 & 1.55 & 22.1 & $0.91 \pm 0.01^{\mathrm{a}}$ & $1.01 \pm 0.01^{b}$ \\
\hline RFI & 935 & $0 \pm 1.53$ & -4.41 & 4.40 & $N R$ & $-0.40 \pm 0.06^{\mathrm{a}}$ & $0.09 \pm 0.07^{b}$ \\
\hline
\end{tabular}

'BWi and BWf: BW at the beginning and at the end of the Fl period (in g), respectively; TGC $_{\text {Loss }}$ Loss of weight during the fasting period estimated as thermal growth coefficient during the fasting period, $T G C_{\text {СОMP }}$ Gain of weight during the feeding period estimated as the thermal growth coefficient during the refeeding period, BWG Body weight gain during the FI period (g), $T G C_{F I}$ Thermal growth coefficient during the Fl period, Fl Feed intake (g), FCR Feed conversion ratio ( $\mathrm{g} . \mathrm{g}^{-1}$ ), RFI Residual feed intake (g)

NR CV are not relevant in these cases

${ }^{a-b}$ LS Means within row with different superscript are significantly different $(P$-value $<0.05)$ 
Table 2 Estimates ( \pm standard error) of heritability (highlighted in grey, on the diagonal), genetic correlations (above diagonal) and phenotypic correlations (below diagonal) for all the traits measured

\begin{tabular}{|c|c|c|c|c|c|c|c|c|c|}
\hline \multicolumn{8}{|c|}{ Growth traits and feed intake } & \multicolumn{2}{|c|}{ Feed efficiency traits } \\
\hline Trait1 & BWi & BWf & TGC LOSS & $\mathrm{TGC}_{\text {СOMP }}$ & BWG & $\mathrm{TGC}_{\mathrm{Fl}}$ & $\mathrm{FI}$ & FCR & $\mathrm{RFI}$ \\
\hline \multicolumn{10}{|c|}{ Growth traits and feed intake } \\
\hline BWi & $0.65 \pm 0.11$ & $0.99 \pm 0.01$ & $0.08 \pm 0.26$ & ne & $0.86 \pm 0.08$ & $0.33 \pm 0.26$ & $0.77 \pm 0.08$ & $0.11 \pm 0.21$ & $0.01 \pm 0.18$ \\
\hline BWf & 0.95 & $0.60 \pm 0.11$ & $-0.01 \pm 0.25$ & ne & $0.93 \pm 0.04$ & $0.47 \pm 0.21$ & $0.77 \pm 0.08$ & $0.08 \pm 0.22$ & $0.07 \pm 0.19$ \\
\hline $\mathrm{TGC}_{\text {LosS }}$ & 0.03 & 0.02 & $0.23 \pm 0.12$ & $0.15 \pm 0.29$ & $-0.18 \pm 0.29$ & $-0.46 \pm 0.41$ & $0.46 \pm 0.24$ & $0.80 \pm 0.25$ & $0.70 \pm 0.22$ \\
\hline $\mathrm{TGC}_{\text {СOMP }}$ & 0.80 & 0.80 & 0.07 & $0.22 \pm 0.06$ & $0.70 \pm 0.17$ & $0.73 \pm 0.26$ & $0.55 \pm 0.15$ & $0.18 \pm 0.22$ & $0.19 \pm 0.23$ \\
\hline WG & 0.63 & 0.85 & -0.02 & 0.64 & $0.27 \pm 0.08$ & $0.75 \pm 0.14$ & $0.62 \pm 0.13$ & $-0.07 \pm 0.24$ & $-0.14 \pm 0.22$ \\
\hline $\mathrm{TGC}_{\mathrm{FI}}$ & 0.26 & 0.54 & -0.03 & 0.41 & 0.88 & $0.10 \pm 0.06$ & $0.25 \pm 0.26$ & $-0.29 \pm 0.28$ & $-0.30 \pm 0.25$ \\
\hline $\mathrm{FI}$ & 0.6 & 0.69 & 0.05 & 0.52 & 0.67 & 0.53 & $0.45 \pm 0.09$ & $0.67 \pm 0.15$ & $0.63 \pm 0.12$ \\
\hline \multicolumn{10}{|c|}{ Feed efficiency traits } \\
\hline FCR & -0.11 & -0.25 & 0.09 & -0.19 & -0.46 & -0.55 & 0.26 & $0.32 \pm 0.11$ & $0.97 \pm 0.03$ \\
\hline RFI & -0.17 & -0.18 & 0.09 & -0.18 & -0.22 & -0.19 & 0.46 & 0.83 & $0.50 \pm 0.10$ \\
\hline
\end{tabular}

Bold indicates that the estimate significantly differs from zero

ne Non estimable due to a non-convergence of the estimation model

${ }^{1} \mathrm{BWi}$ and BWf: BW at the beginning and at the end of the FI period, respectively; TGCLOSS Loss of weight during the fasting period estimated as thermal growth coefficient during the fasting period, TGCCOMP Gain of weight during the feeding period estimated as the thermal growth coefficient during the refeeding period, $B W G$ Body weight gain during the FI period, $T G C_{F I}$ Thermal growth coefficient during the FI period, FI Feed intake, $F C R$ Feed conversion ratio, $R F I$ Residual feed intake

generation, for a selection for BWf and BWi, respectively).

Selection for growth characteristics other than BW (BWG or $\mathrm{TGC}_{\mathrm{FI}}$ ) would improve growth, as expected, but would not improve FCR.

Selection for FCR or RFI would improve FCR by 0.150 and 0.181 per generation, representing an improvement of FCR by 16.0 and $19.3 \%$ per generation of selection.
Such selection would not influence body weight and BWG of the fish, and would moderately reduce $\mathrm{TGC}_{\mathrm{FI}}$ (by $4.02 \mathrm{e}^{-3}$ and $5.09 \mathrm{e}^{-3}$, respectively, representing a decrease of $\mathrm{TGC}_{\mathrm{FI}}$ of 2.5 to $3.2 \%$ per generation) and reduce FI (by 14.3 and $16.8 \%$ per generation).

Finally, it is important to highlight that selecting for $\mathrm{TGC}_{\mathrm{LOSS}}$ would improve FCR by $10.9 \%$ per generation (representing $0.102 \mathrm{~g} \cdot \mathrm{g}^{-1}$ ).

Table 3 Expected responses (expressed in unit of the trait improved) to direct selection (diagonal, in grey) or to indirect selection on body weight and growth variation (BWi, BWf, TGC $\left.C_{\text {LOSS, }} \mathrm{TGC}_{\mathrm{COMP}}, \mathrm{BWG}_{\mathrm{TG}} \mathrm{TG}_{\mathrm{FI}}\right)^{1}$ and on feed intake and efficiency $(\mathrm{FI}, \mathrm{FCR}, \mathrm{RFI})^{2}$ if one trait is used in the selective breeding program

\begin{tabular}{|c|c|c|c|c|c|c|c|c|c|}
\hline \multirow[t]{3}{*}{ Traits $^{2}$} & \multicolumn{7}{|c|}{ Selection objective } & & \\
\hline & \multicolumn{7}{|c|}{ Growth traits and feed intake } & \multicolumn{2}{|c|}{ Feed efficiency traits } \\
\hline & BWi & BWf & $\mathrm{TGC}_{\text {LOSS }}$ & TGC COMP & BWG & $\mathrm{TGC}_{\mathrm{FI}}$ & $\mathrm{Fl}$ & FCR & RFI \\
\hline \multicolumn{10}{|c|}{ Selection criterion $^{1}$} \\
\hline BWi & 7.21 & 9.81 & $4.22 \mathrm{e}-04$ & . & 2.21 & $6.67 e-3$ & 1.99 & 0.02 & 0.02 \\
\hline BWf & 6.70 & 9.34 & $4.49 \mathrm{e}-05$ & . & 2.27 & $8.93 e-3$ & 1.88 & 0.02 & 0.12 \\
\hline $\mathrm{TGC}_{\text {LOSS }}$ & 0.34 & 0.06 & $4.19 e-03$ & $3.46 e-03$ & 0.27 & $5.44 \mathrm{e}-3$ & 0.70 & 0.10 & 0.82 \\
\hline $\mathrm{TGC}_{\text {СOMP }}$ & . & . & $6.12 \mathrm{e}-04$ & $2.25 e-02$ & 1.04 & $8.41 e-3$ & 0.81 & 0.02 & 0.22 \\
\hline BWG & 3.89 & 5.83 & $8.10 e-04$ & $1.74 \mathrm{e}-02$ & 1.63 & $9.49 e-3$ & 1.02 & -0.01 & -0.18 \\
\hline $\mathrm{TGC}_{\mathrm{FI}}$ & 0.92 & 1.81 & $3.28 e-03$ & $2.87 e-02$ & 0.75 & $7.79 e-3$ & 0.25 & -0.02 & -0.23 \\
\hline $\mathrm{FI}$ & 4.40 & 6.08 & $2.60 \mathrm{e}-03$ & $1.72 \mathrm{e}-02$ & 1.28 & $3.95 e-3$ & 2.05 & 0.13 & 1.00 \\
\hline FCR & 0.53 & 0.51 & $3.92 e-03$ & 4.87e-03 & -0.12 & $-4.02 e-3$ & 1.19 & 0.15 & 1.34 \\
\hline RFI & 0.06 & 0.55 & $4.27 e-03$ & $6.39 e-03$ & -0.31 & $-5.09 e-3$ & 1.4 & 0.18 & 1.71 \\
\hline
\end{tabular}

Bolds indicate high (> 75\%) expected responses, respectively

${ }^{1}$ As an example, select for FCR would improve FCR by $0.15 \mathrm{~g} \cdot \mathrm{g}^{-1}$ at each generation of selection, but would reduce BWG by $0.12 \mathrm{~g}$, whereas select for BWG would increase BWG by $1.63 \mathrm{~g}$ but will not improve FCR, as the expected response to selection is $-0.01 \mathrm{~g} \cdot \mathrm{g}^{-1}$

${ }^{2} \mathrm{BWi}$ and BWf: BW in $\mathrm{g}$ at the beginning and at the end of the FI period, respectively; TGCLOSS Loss of weight during the fasting period estimated as thermal growth coefficient during the fasting period, TGCCOMP Gain of weight during the feeding period estimated as the thermal growth coefficient during the refeeding period, BWG Body weight gain in g during the FI period, $T G C_{F I}$ Thermal growth coefficient during the FI period, FI Feed intake in $\mathrm{g}$, $F C R$ Feed conversion ratio in $\mathrm{g} . \mathrm{g}^{-1}, R F I$ Residual feed intake in $\mathrm{g}$ 


\section{Discussion}

Until now, the very few studies in fish that estimated genetic parameters of individual variation of feed efficiency traits used the X-ray methodology. This method has a poor repeatability of daily feed intake between two records $(r=0.09$ to $0.32[27,30,31])$, and is thus likely to be unreliable since fish show strong variation in FI from meal to meal and from day to day [40, 41]. This problem has been solved by using repeated measurements over a long period of time. Using data with 0.1 to 0.3 repeatability of feed intake between two records, Kause et al. [30] estimated an increase of the repeatability to 0.25 and 0.56 , respectively, when three records were used and until 0.72 if six measurements were recorded and pooled. Conversely, we showed previously that accurate measurement of feed intake of individual fish reared in groups can be achieved using videos assuming appropriate care is taken in the feeding procedure and FI is measured for several consecutive days together with growth [32]. The main advantages of the video method compared to the $\mathrm{X}$-ray method is that it is possible to follow individual feed intake of fish during consecutive meals without stressing the fish by handling or anesthesia. While the results of de Verdal et al. [32] need to be taken carefully because tilapia were juvenile (less than $50 \mathrm{~g}$ and around 3 months at the end of the experiment), it seemed possible to use this methodology to measure accurately feed intake of several consecutive meals. This allowed to estimate accurately FCR and consequently, to estimate with good repeatability, the genetic parameters of feed efficiency. However, we need to highlight that even if the method was accurate, it was used only on juvenile Nile tilapia (final $\mathrm{BW}=32 \mathrm{~g}$ on average), over a short period of time and fish were reared in aquariums, not in ponds, there normal rearing system. Practically speaking, this method also has its drawbacks, i.e. the need to feed fish pellet by pellet and the time needed for video recording analyses.

\section{Heritability of feed efficiency}

The present estimate of FCR heritability is much higher than the few published estimates from previous studies, which ranged from 0 to 0.07 in rainbow trout Oncorhynchus mykiss and European whitefish Coregonus larvaretus $[19,20,31]$ vs. $0.32 \pm 0.11$ in the present study. FI was also more heritable in the present experiment $\left(\mathrm{h}^{2}=\right.$ $0.45 \pm 0.09$ ) compared to published values for salmonids species in the literature, ranging from 0.07 to 0.29 [19, $20,31,42]$. These differences could be partly explained by species differences or fish size differences, since they were not at the same stage of their growth curve, but may also reflect the more accurate methodology used in the present study to measure FI. Importantly, although higher than previous estimates in fish, the present results are in line with genetic parameters found in terrestrial livestock species such as chicken $\left(\mathrm{h}^{2}{ }_{\mathrm{FCR}}=0.21\right.$ $\left.\pm 0.02, h_{R F I}^{2}=0.46 \pm 0.06[25]\right)$ and pigs $\left(h^{2}{ }_{F C R}=0.34 \pm\right.$ 0.05 and $h_{\text {RFI }}^{2} 0.26 \pm 0.05$ on average [24]). More accurate data from a range of fish species will however be required to settle the matter generally.

The demonstration of moderately to highly heritable FCR and RFI strongly suggests that a selective breeding program including these traits could efficiently improve feed efficiency. The high genetic correlations between FCR and RFI suggests these two traits are driven by the same genetic basis or represent the same trait, and that the improvement of one of these traits would improve the other one.

However, it is important to remind that fish studied in the present study were juvenile Nile tilapia. It could be interesting to try the same experiment on other fish species and at different ages to ensure that a selective breeding program will have an impact on all the rearing period rather than just at small range of fish size.

\section{Correlations of growth and feed efficiency traits}

FCR is particularly difficult to measure directly on candidates in breeding programs. The present method, albeit accurate, requested the analysis of around $280 \mathrm{~h}$ of video recordings to evaluate 1004 fish. Thus, we also assessed different strategies for improving FCR given the correlations with other growth traits that are easier to measure and are already recorded in fish breeding programs. Using phenotypic information, several authors predicted that selection for growth in fish should be associated with an improvement of feed efficiency [8, 18, 21], as phenotypic correlation between feed efficiency and growth ranges from 0.6 to 0.9 . In the present study, while the phenotypic correlations between BWG, $\mathrm{TGC}_{\mathrm{FI}}$ and FCR were moderate ( -0.46 and -0.55 , respectively), the genetic correlation were low and not significantly different from zero $(-0.07 \pm 0.24$ and $-0.29 \pm 0.28$, respectively). Thus, we expect that contrary to the general thinking, selection for growth (BWG or $\mathrm{TGC}_{\mathrm{FI}}$ ) would not induce a correlated response on FCR, and the same was true for RFI. Selecting for BWG would improve BWG by $1.63 \mathrm{~g}$ at each generation, a $17.5 \%$ improvement per generation, but would decrease FCR by $0.009 \mathrm{~g}^{\mathrm{g}} \mathrm{g}^{-1}$ at each generation (corresponding to an improvement of $0.96 \%$ of FCR at each generation). On the other hand, selecting tilapia for FCR would decrease FCR by 0.15 g.g ${ }^{-1}$ at each generation of selection, corresponding to a $16 \%$ improvement of FCR at each generation, but would increase BWG by only $0.12 \mathrm{~g}(1.26 \%)$ at each generation. These results differ from previous results using the X-ray methodology reported by Kause, et al. [19] and Quinton, et al. [20] who estimated that selection for high growth would substantially improve FCR 
as a correlated response. These different results could be explained by the methodology used to measure FCR but also by the fish species as the present work was performed on tropical freshwater fish rather than previous works were done on saline seawater fish adapted to cold water temperature. From the statement that the basal metabolism is high on tropical fish than on cold water [43], it could be hypothesize that part of the feed consumed by a tropical fish is not going to the growth whereas in cold water fish species, almost all the FI is going through the growth, and consequently, the correlation between FCR and growth would be higher in cold water than in tropical water fish species.

Furthermore, the age of the fish could have an impact on these correlations between FCR and growth. More work is needed to clarify these results.

\section{Practical traits and strategies for selection of feed efficiency}

Successful use of a trait in a selective breeding program requires the trait to be accurately measured. Although the approach of de Verdal et al. [32] used in this study permitted an accurate measurement of individual feed intake and thus of FCR on 40 families, the method was time consuming and impractical for application in industry selection programs. The generation time of Nile tilapia is around 1 year and the selection criterion would need to be measured on all the fish (usually 100 or more families) within 1 year to be useful. Even if one were able to imagine a more efficient scale up within an industrial process the cost of such an approach is likely to be prohibitive.

An alternative and powerful way to add FCR or RFI into a selective breeding program would be to find easily measurable traits highly correlated with FCR or RFI. It was previously shown that the loss of weight during fasting and the gain of weight during compensatory growth were heritable and phenotypically correlated with RFI in European sea bass and rainbow trout Oncorhynchus mykiss [27, 44]. Heritability estimates for those traits in the present study were comparable to the estimations previously obtained on sea bass by Grima et al. [44]. These authors also concluded that compensatory growth when refeeding after a fasting period was not a useful trait to use to improve FCR in sea bass. The present results from tilapia were similar, and in our case this result was explained by the low genetic correlations between $\mathrm{TGC}_{\mathrm{COMP}}$ and FCR or RFI.

However, selecting fish for $\mathrm{TGC}_{\mathrm{LOSS}}$ could have a high impact in terms of FCR improvement. The genetic correlation between FCR and the loss of weight during fasting $\left(\mathrm{TGC}_{\mathrm{LOSS}}\right)$ was high $(0.80 \pm 0.25)$. As $\mathrm{TGC}_{\mathrm{LOSS}}$ is easy to measure in fish, since it is just growth measured during a period of fasting, it could be an efficient indirect selection criterion to improve FCR. Selecting Nile tilapia for high $\mathrm{TGC}_{\mathrm{LOSS}}$ could improve FCR by $0.102 \mathrm{~g} . \mathrm{g}^{-1}$ (corresponding to $68.3 \%$ of a direct selection for FCR), representing an improvement of $10.9 \%$ of FCR at each generation of selection.

These results are surprising and not expected, as the previous reports estimating the correlations between the loss of weight during fasting and feed efficiency were in the opposite direction. Grima et al. [44] estimated that sea bass losing less weight during fasting were more efficient at converting feed into body mass. The contrasting results from sea bass and tilapia might be explained in three ways. Firstly, Grima et al. [44] measured a group of 50 fish rather than individual fish, and the correlation was a phenotypic correlation rather than a genetic correlation. At the phenotypic level, the present correlation between the loss of weight and FCR was not significantly different from zero. Secondly, sea bass lives in a relatively cold temperature and in seawater, while Nile Tilapia is a warm freshwater fish. It is possible that these two species do not store and use the same compartments (lipid, protein) in response to fasting. For example, for the same body weight, sea bass has much more perivisceral fat than tilapia and several authors have highlighted a relationship between feed efficiency and lipid percentage in cold water fish species C. larvaretus and O. mykiss [23, 31]. Thirdly, it is important to note that the present tilapia study focused on relatively small (around $30 \mathrm{~g}$ ) and young fish (around 3 months) while those on sea bass were larger $(50 \mathrm{~g})$ and older (1 year to 18 months). It will be important to check for tilapia (or for any target species) if the genetic variation and correlations between traits are stable along time and the age at which selection is most effective. Recording individual FI and FCR is certainly easier in younger fish, but the impact of improving FCR on environment and economy is higher on larger fish. In this respect, if $\mathrm{TGC}_{\mathrm{LOSS}}$ was also a good indirect selection trait for FCR in larger fish, it would be highly valuable as it remains easy to measure at any age.

\section{Conclusion}

Our results demonstrated strong genetic control of FCR and RFI in juvenile Nile tilapia. Importantly, they demonstrated that at this age, improvements in FCR would not be achieved effectively by selection on growth alone in Nile tilapia. The estimates of response to selection under a number of selection strategies calculated from these data showed that FCR could be efficiently improved by direct selection or by indirect selection on RFI. However, both require tedious and time consuming measurement of individual feed intake. It is also important to highlight that fish studied here were juvenile. At the production level, feed is mainly consumed when fish 
are reaching harvest weight. Consequently, an estimation of the evolution of feed efficiency with the age of the tilapia could be helpful to understand at what age fish should be selected for feed efficiency improvement.

Interestingly, indirect selection for the relative weight loss at fasting would also yield substantial gains in FCR, and be much easier to implement. Additional work is required to measure FCR on older/larger fish and to estimate the impact of the fish age when the fasting period is performed. Furthermore, given the growing range and cost effectiveness of genomic tools, it could be particularly interesting to study the markers associated with FCR in view to use the genomic selection approaches to improve FCR. Our results show that selective breeding for feed efficiency in fish would be possible and would help enabling the development of a more sustainable aquaculture.

\begin{abstract}
Abbreviations
BW: Body weight; BWG: Body weight gain during the Fl period; FCR: Feed conversion ratio during the Fl period; Fl: Feed intake measured for each fish reared in group; RFI: Residual feed intake during the FI period; TGC Comp: Gain of weight during the feeding period estimated as the thermal growth coefficient during the refeeding period; $\mathrm{TGC}_{\mathrm{Fl}}$ : Thermal growth coefficient during the FI period; TGCLoss: Loss of weight during the fasting period estimated as thermal growth coefficient during the fasting period
\end{abstract}

\section{Acknowledgements}

We thank Hooi Ling Khaw, Hoong Yip Yee and Khairul Rizal Abu Bakar for the supply of fish and maintenance of the water system, Marie-Laure Bégout for advice on visual tagging, and colleagues who improved this work through commenting on earlier drafts.

\section{Funding}

The design of the study, the collection of the data, the analysis and interpretation of the results and the writing of the paper was performed with the support of the Livestock and Fish CGIAR Research Program and on the FISH CGIAR Research Program. Funding bodies did not have any influence on the scientific analysis and interpretation of the study.

\section{Availability of data and materials}

The datasets used and/or analysed during the current study are available from the corresponding author on reasonable request.

\section{Authors' contributions}

H.d.V. designed and performed research; H.d.V., W.M. and M.V. analyzed data; H.d.V., M.V., W.M., B.C. and J.A.H.B. wrote the paper. All authors read and approved the final manuscript.

\section{Ethics approval and consent to participate}

Approved by the internal WorldFish ethics committee. The fish were derived from the WorldFish breeding programme developed in the WorldFish breeding station in Malaysia. All the parties agreed for this experiment.

\section{Consent for publication}

Not applicable.

\section{Competing interests}

The authors declare that they have no competing interests.

\section{Publisher's Note}

Springer Nature remains neutral with regard to jurisdictional claims in published maps and institutional affiliations.

\section{Author details}

${ }^{1}$ CIRAD, UMR116 ISEM, TA B-116/16, 73 rue Jean-François Breton, 34398 Montpellier Cedex 5, France. ${ }^{2}$ Worldfish, Jalan Batu Maung, 11960 Bayan Lepas, Penang, Malaysia. ${ }^{3} \mathrm{GABI}$, INRA, AgroParisTech, Université Paris-Saclay, F-78350 Jouy-en-Josas, France. ${ }^{4}$ Ifremer, UMR9190 MARBEC, Chemin de Maguelone, F-34250 Palavas-les-Flots, France. ${ }^{5}$ Animal Production Department, Faculty of Agriculture, Ain Shams University, Hadaeq Shubra, Cairo 11241, Egypt. ${ }^{6}$ School Of Biological Earth and Environmental Sciences, University College Cork, Cork, Ireland.

Received: 1 December 2017 Accepted: 31 October 2018 Published online: 16 November 2018

\section{References}

1. United Nations. World population prospects: the 2015 revision, key findings and advance tables. Working paper no. ESA/P/WP.241. 2015.

2. FAO. How to feed the world in 2050. 2015.

3. FAO. The state of world fisheries and aquaculture 2016. Contributing to food security and nutrition for all. 2016; 22/03/2016.

4. Earth Policy Institute. World animal production by type, 1950-2012. 2013

5. Welch A, Hoenig R, Stieglitz J, Benetti D, Tacon AGJ, Sims N, et al. From fishing to the sustainable farming of carnivorous marine finfish. Rev Fish Sci. 2010;18:235-47.

6. de Verdal H, Rosario W, Vandeputte M, Muyalde N, Morissens P, Baroiller J-F, et al. Response to selection for growth in an interspecific hybrid between Oreochromis mossambicus and O. niloticus in two distinct environments. Aquaculture. 2014;430:159-65.

7. Doupé RG, Lymbery AJ. Indicators of genetic variation for feed conversion efficiency in black bream. Aquac Res. 2004;35:1305-9.

8. Kolstad K, Grisdale-Helland B, Gjerde B. Family differences in feed efficiency in Atlantic salmon (Salmo salar). Aquaculture. 2004;241:169-77.

9. de Verdal H, Komen H, Quillet E, Chatain B, Allal F, Benzie J. A. H, et al. (2017a). Improving feed efficiency in fish using selective breeding: a review. Rev Aquac.10:833-851

10. Huntington TC, Hasan MR. Fish as feed inputs for aquaculture - practice, sustainibility and implications: a global synthesis. In: Hasan MR, Halwart M, editors. Fish as feed inputs for aquaculture: practices, sustainability and implications. Rome: FAO: Fisheries and aquaculture technical paper; 2009. p. 1-61.

11. Aubin J, Papatryphon E, Van der Werf JHJ, Chatzifotis S. Assessment of the environmental impact of carnivorous finfish production systems using life cycle assessment. J Clean Prod. 2009;17:354-61.

12. Gaylord TG, Gatlin IIIDM. Dietary protein and energy modifications to maximize compensatory growth of channel catfish (Ictalurus punctatus). Aquaculture. 2001;194:337-48.

13. Guroy B, Sahin I, Kayali S, Mantoglu S, Canan B, Merrifield DL, et al. Evaluation of feed utilization and growth performance of juvenile striped catfish Pangasianodon hypophtalmus fed with varying inclusion levels of corn gluten meal. Aquac Nutr. 2013;19:258-66.

14. Reigh RC, Ellis SC. Effects of dietary soybean and fish-protein ratios on growth and body-composition of red drum (Sciaenops ocellatus) fed isonitrogenous diests. Aquaculture. 1992;104:279-92.

15. Cho CY. Bureau DP. A review of diet formulation strategies and feeding systems to reduce excretory and feed wastes in aquaculture. Aquac Res. 2001;32:349-60.

16. Turchini GM, Torstensen BE, Ng W-K. Fish oil replacement in finfish nutrition. Rev Aquac. 2009;1:10-57.

17. Emmerson DA. Commercial approaches to genetic selection for growthand feed conversion in domestic poultry. Poult Sci. 1997;76:1121-5.

18. Henryon M, Jokumsen A, Berg P, Lund I, Pedersen PB, Olesen NJ, et al. Genetic variation for growth rate, feed conversion efficiency, and disease resistance exists within a farmed population of rainbow trout. Aquaculture. 2002;209:59-76

19. Kause A, Tobin D, Houlihan DF, Martin SAM, Mäntysaari EA, Ritola O, et al. Feed efficiency of rainbow trout can be improved through selection: different genetic potential on alternative diets. J Anim Sci. 2006;84:807-17.

20. Quinton CD, Kause A, Koskela J, Ritola O. Breeding salmonids for feed efficiency in current fishmeal and future plant-based diet environment. Genet Sel Evol. 2007:39:431-46.

21. Thodesen J, Grisdale-Helland B, Helland SJ, Gjerde B. Feed intake, growth and feed utilization of offsring from wild and selected Atlantic salmon (Salmo salar). Aquaculture. 1999;180:237-46. 
22. Ogata HY, Oku H, Murai T. Growth, feed efficiency and feed intake of offspring from selected and wild Japanese flounder (Paralichthys olivaceus). Aquaculture. 2002;211:183-93.

23. Kause A, Kiessling A, Martin SAM, Houlihan D, Ruohonen K. Genetic improvement of feed conversion ratio via indirect selection against lipid deposition in farmed rainbow trout (Oncorhynchus mykiss Walbaun). Br J Nutr. 2016;116:1656-65.

24. Saintilan R, Mérour I, Brossard L, Tribout T, Dourmad JY, Sellier P, et al. Genetics of residual feed intake in growing pigs: relationships with production traits, and nitrogen and phosphorus excretion traits. J Anim Sci. 2013;91:2542-54.

25. de Verdal H, Narcy A, Bastianelli D, Chapuis H, Même N, Urvoix S, et al. Improving the efficiency of feed utilization in poultry by selection. 1. Genetic parameters of anatomy of the gastro-intestinal tract and digestive efficiency. BMC Genet. 2011;12:59.

26. Gjedrem T. Genetic variation in quantitative traits and selective breeding in fish and shellfish. Aquaculture. 1983;33:51-72.

27. Grima L, Quillet E, Boujard T, Robert-Granié C, Chatain B, Mambrini M. Genetic variability in residual feed intake in rainbow trout clones and testing of indirect selection criteria. Genet Sel Evol. 2008;40:607-24.

28. McCarthy ID, Houlihan DF, Carter CG, Moutou K. Variation in individual food consumption rates of fish and its implications for the study of fish nutrition and physiology. Proc Nutr Soc. 1993;52:427-36.

29. Talbot C. Higgins PJ. A radiographic method for feeding studies on fish using metallic iron powder as a marker. J Fish Biol. 1983;23:211-20.

30. Kause A, Tobin D, Dobly A, Houlihan D, Martin S, Mäntysaari EA, et al. Recording strategies and selection potential of feed intake measured using the X-ray method in rainbow trout. Genet Sel Evol. 2006;38:389-409.

31. Quinton CD, Kause A, Ruohonen K, Koskela J. Genetic relationships of body composition and feed utilization traits in European whitefish (Coregonus larvaretus L.) and implications for selective breeding in fishmeal- and soybean meal-based diet environments. J Anim Sci. 2007;85:3198-208.

32. de Verdal H, Mekkawy W, Lind CE, Vandeputte M, Chatain B, Benzie J. Measuring individual feed efficiency and its correlations with performance traits in Nile tilapia, Oreochromis niloticus. Aquaculture. 2017;468:489-95.

33. Ponzoni RW, Hong Nguyen N, Khaw HL, Hamzah A, Abu Bakar KR, Yee HY. Genetic improvement of Nile tilapia (Oreochromis niloticus) with special reference to the work conducted by the WorldFish center with the GIFT strain. Rev Aquac. 2011;3:27-41.

34. Mélard C, Baras E, Desprez D. Compensatory growth of Nile tilapia Oreochromis niloticus. Fourth international symposium on Tilapia in Aquaculture; 1997.

35. Koch RM, Swiger LA, Chambers D, Gregory KE. Efficiency of feed use in beef cattle. J Anim Sci. 1963;22:486-94.

36. Lupatsch I, Kissil GW, Sklan D. Comparison of energy and protein efficiency among three fish species gilthead sea bream (Sparus aurata), European sea bass (Dicentrarchus labrax) and white grouper (Epinephelus aeneus): energy expenditure for protein and lipid deposition. Aquaculture. 2003;225:175-89.

37. Kovac M, Groeneveld E, Garcia-Cortez A. VCE 6 User's manual. version 6. $0.2 ; 2008$.

38. Neumaier A, Groeneveld E. Restricted maximum likelihood of covariances in sparse linear models. Genet Sel Evol. 1998;30:13-26.

39. Falconer DS, MacKay TFC. Introduction to quantitative genetics. 4th ed. Burnt Mill, Harlow: Longman Scientific \& Technical; 1996.

40. Alanärä $A$, Kadri S, Paspatis M. Feeding management. In: Houlihan D, Boujard T, Jobling M, editors. Food intake in fish. Oxford: Blackwell Science Ltd Editorial Offices: Osney Mead; 2001. p. 332-53.

41. McCarthy ID, Carter CG, Houlihan DF. The effect of feeding hierarchy on individual variability in daily feeding of rainbow trout, Oncorhynchus mykiss (Walbaum). J Fish Biol. 1992;41:257-63.

42. Sanchez M-P, Chevassus B, Labbé L, Quillet E, Mambrini M. Selection for growth of brown trout (Salmo trutta) affects feed intake but not feed efficiency. Aquat Living Resour. 2001;14:41-8.

43. Clarke A, Johnston NM. Scaling of metabolic rate with body mass and temperature in teleost fish. J Anim Ecol. 1999;68:893-905. https://doi.org/10. 1046/j.1365-2656.1999.00337.x.

44. Grima L, Vandeputte M, Ruelle F, Vergnet A, Mambrini M, Chatain B. In search for indirect criteria to improve residual feed intake in sea bass (Dicentrarchus labrax). Part I: phenotypic relationship between residual feed intake and body weight variations during feed deprivation and re-feeding periods. Aquaculture. 2010;300:50-8.

Ready to submit your research? Choose BMC and benefit from:

- fast, convenient online submission

- thorough peer review by experienced researchers in your field

- rapid publication on acceptance

- support for research data, including large and complex data types

- gold Open Access which fosters wider collaboration and increased citations

- maximum visibility for your research: over $100 \mathrm{M}$ website views per year

At BMC, research is always in progress.

Learn more biomedcentral.com/submissions 